\title{
Possibilidades de trabalho social com as famílias inseridas no Serviço de Proteção e Atendimento integral à Família - PAIF
}

\author{
Possibilities of social work with the families included in the Service of Protection and \\ Integral Assistance to the Family - PAIF
}

\author{
Cristiane Gonçalves de Souza* \\ Jussara Ayres Bourguignon**
}

\begin{abstract}
Resumo:
$\mathrm{O}$ artigo propõe refletir sobre os pressupostos do trabalho social com as famílias inseridas no PAIF (Serviço de Proteção e Atendimento Integral à Família). Tais pressupostos são pontuados reconhecendo o contexto contemporâneo de regressão e fragmentação das políticas públicas e tendo no horizonte a necessidade de superar a responsabilização da família quanto à proteção social de seus membros. Para tanto, pautou-se em pesquisa bibliográfica e documental. As reflexões foram organizadas em três momentos articulados: a proteção social básica no âmbito do SUAS (Sistema Único de Assistência Social) e a contextualização do PAIF; a filosofia da práxis enquanto mobilizadores das práticas profissionais; trabalho social com famílias. Diante dos elementos trabalhados, pontuam-se desafios à prática profissional no contexto do PAIF. Tais desafios apontam para o rompimento e a superação de práticas conservadoras, em uma perspectiva de enquadramento e responsabilização das famílias, avançando para metodologias que fortaleçam o protagonismo das mesmas, mediante oferta de serviços de qualidade e articulados às demais políticas públicas. $O$ texto reforça que o protagonismo não significa isentar o Estado de sua responsabilidade de garantir proteção social às famílias que estão em condição de vulnerabilidade e risco social.
\end{abstract}

Palavras-chave: Política Pública de Assistência Social. Família. Trabalho social.

\begin{abstract}
:
The article proposes to reflect on the assumptions of social work with the families included in the PAIF (Service of Protection and Integral Assistance to the Family). Such assumptions are punctuated by recognizing the contemporary context of regression and fragmentation of public policies and having on the horizon the need to overcome the family's responsibility for the social protection of its members. For that, it was based on bibliographical and documentary research. The reflections were organized in three articulated moments: the basic social protection in the ambit of the SUAS (Unified System of Social Welfare) and the contextualization of the PAIF; the philosophy of praxis as mobilizers of professional practices; social work with families. In view of the elements worked on, challenges to professional practice in the PAIF context are highlighted. These challenges point out to the disruption and overcoming of conservative practices, from a perspective of framing and accountability of families, advancing to methodologies that strengthen the protagonism of them, by offering quality services and articulated to other public policies. The text reinforces that the protagonism does not mean to exempt the State from its responsibility of guaranteeing social protection to the families that are in condition of vulnerability and social risk.
\end{abstract}

Keywords: Public Policy of Social Assistance. Family. Social work.

\footnotetext{
* Professora do Departamento de Serviço Social e Doutora em Ciências Sociais Aplicadas da Universidade Estadual de Ponta Grossa/Pr.

** Professora do Departamento de Serviço Social e do Programa de Pós-Graduação em Ciências Sociais Aplicadas. Doutora em Serviço Social pela PUC de São Paulo.
} 


\section{Introdução}

Este artigo apresenta como objetivo refletir sobre os pressupostos do trabalho social com as famílias no PAIF (Serviço de Proteção e atendimento integral à Família). Tais pressupostos estão assentados na concepção de proteção social estabelecido pelo SUAS (Sistema Único de Assistência Social) e pela perspectiva gramsciana de filosofia da práxis.

A filosofia da práxis, sustentada em Gramsci, é referência para pautar as práticas profissionais no âmbito do PAIF. As metodologias de intervenção com famílias, neste contexto, são problematizadas a partir de elementos que envolvem desde os processos de gestão da política de Assistência Social até a intervenção direcionada para os níveis de prestação de serviços socioassistenciais.

As reflexões empreendidas reconhecem o direito à proteção social, que deve ser potencializada pela rede de serviços socioassistenciais no âmbito da PNAS (Política Nacional de Assistência Social), fazendo frente aos processos de responsabilização da família que decorrem da ofensiva neoliberal.

\section{O SUAS e as ações do PAIF no contexto da Proteção Social Básica}

Com a Constituição Federal (CF) de 1988 a Assistência Social ${ }^{1}$ ganha status de Política Social Pública, compondo junto com a Saúde e Previdência Social o Sistema de Seguridade Social Brasileiro, através dessa nova configuração estabeleceu-se um campo fértil e ao mesmo tempo de avanços e desafios referente à assistência social como política.

Desde a CF de 1988, a assistência social vem construindo uma nova trajetória, organizando-se sob novos padrões e afirmando-se como parte integrante do sistema brasileiro de proteção social. Como política social asseguradora de direitos, no âmbito da seguridade social, a assistência passou por expressivas alterações, que ocorreram, e ainda estão se desenvolvendo, com vistas a enfrentar um contexto histórico de negligência e omissão do Estado em relação às ações de dominação social e assistencialistas, caritativas e improvisadas que marcavam as intervenções junto à área da assistência social (JACCOUD, 2009).

As ações realizadas na área da assistência social passam a ser tratadas não mais como ato de bondade e caridade, sem planejamento ou agenda. Na verdade, é a partir

\footnotetext{
${ }^{1}$ Para maiores detalhes da Trajetória da Assistência Social consultar SCHONS, Selma Maria. Assistência Social entre a Ordem e a Des-Ordem: Mistificação dos direitos sociais e da cidadania. São Paulo: Cortez, 1999.
} 
desse contexto que a assistência social entra na agenda política e então se exige um planejamento rigoroso para implementar suas ações, isso demanda ainda a participação de profissionais qualificados, fato que altera o antigo quadro das damas de caridade e do voluntarismo, que agiam no improviso, com ações fragmentadas.

Com vistas a legitimar o conteúdo explicitado na CF, no ano de 1993 uma importante legislação é aprovada, a Lei Orgânica da Assistência Social (LOAS) promoveu a regulamentação do conteúdo disposto na CF de 1988. No texto da LOAS é possível verificar a lógica de reafirmar a assistência social como um direito social, pois sinaliza que é objetivo da Política de Assistência Social prover os mínimos sociais e que isso se faria mediante um conjunto integrado de ações. Isto implica em compreender que somente a assistência social não tem como dar respostas a todas as demandas dos usuários, para tanto é fundamental o trabalho em rede com as outras políticas (BRASIL, 2005).

Nos anos que se seguiram várias ações foram estabelecidas com intuito de afirmar e legitimar a assistência social como política pública de cidadania, tais ações tinham como foco principal qualificar o rol de programas, projetos, serviços e benefícios desenvolvidos na área da assistência. Como exemplo das ações destacam-se as normativas, as conferências de assistência social que se realizaram, e ainda são realizadas, com finalidade de promover intenso debate em âmbito federal, estadual e municipal a respeito do fortalecimento e adensamento das ações realizadas na área da assistência social promovendo ampliação dos direitos sociais dos usuários desta política.

Tais ações, que contribuíram para qualificar a assistência social sob a lógica de direito social, tiveram em seu bojo um intenso processo de correlação de forças. Ou seja, envolveu intensa mobilização de sujeitos que se colocaram em defesa da assistência social como política pública mediante reconhecimento de que as vulnerabilidades, riscos sociais, desigualdade e pobreza são geradas pelo modo de produção capitalista e não pela simples apatia/fatalismo dos usuários dos serviços da assistência social. Diante de tal constatação, cabe ao Estado intervir estabelecendo ações que promovam a assistência social na lógica de direito e não benesse.

Em 2004 é editada a Política Nacional de Assistência Social (PNAS) que está em vigor e trata da implantação, em território nacional, do Sistema Único de Assistência Social (SUAS); em 2005 é editada a Norma Operacional Básica do Sistema Único de Assistência Social (NOB-SUAS) e em 2006 é aprovada a Norma Operacional Básica de Recursos 
Humanos (NOB-RH), a qual tem como objetivo regular a gestão do trabalho no âmbito do SUAS. Em 2009 é aprovada a Lei no 12.201 que dispõe sobre a certificação das entidades beneficentes de assistência social, também neste ano é aprovada a Resolução no 109 do Conselho Nacional de Assistência Social (CNAS), esta tipifica os Serviços Socioassistenciais disponíveis no Brasil organizando-os por nível de complexidade. Em 2012 a Resolução de no 33 aprova uma nova NOB-SUAS e, no ano de 2011, é alterada a Lei no 12.435 - LOAS, a mesma passa a ser denominada Lei do SUAS.

O SUAS, em vigor desde o ano de 2005, implementa um regime geral para a gestão da Assistência Social e tem como finalidades: prestar serviços, programas, projetos e benefícios de proteção social básica e especial para famílias, indivíduos e grupos que deles necessitarem; contribuir com a inclusão e equidade dos usuários e grupos específicos; promover o acesso aos bens e serviços socioassistenciais básicos e especiais em área urbana e rural; e assegurar a centralidade da família, garantindo a convivência familiar e comunitária (BRASIL, 2005).

Observa-se que a família ocupa lugar de destaque nas ações a serem desenvolvidas no contexto do SUAS, a julgar que uma série de ações passam a ser realizadas com objetivo de atender demandas de proteção social às famílias que se encontram em vulnerabilidade e risco social. Nesse escopo, os serviços socioassistenciais disponíveis no SUAS são organizados e pautados pela lógica da: proteção social, vigilância socioassistencial e defesa de direitos.

A Assistência Social, enquanto proteção social não contributiva, deve favorecer aquisições materiais, sociais, socioeducativas às famílias e seus membros com vistas a suprir suas necessidades de reprodução social de vida individual e familiar; contribuindo para o desenvolvimento de suas capacidades e talentos para a convivência social, protagonismo e autonomia (BRASIL, 2005).

A proteção social de Assistência Social está hierarquizada em Proteção Social Básica (PSB) e Proteção Social Especial (PSE). No que tange à PSB, objeto deste estudo, a mesma tem como objetivo contribuir para a prevenção de situações de risco, concretizando ações que possam favorecer o desenvolvimento de potencialidades, aquisições e o fortalecimento de vínculos familiares e comunitários (BRASIL, 2005).

A PSB é responsável por prestar atendimento à população que vive em situação de vulnerabilidade social, gerada pela pobreza, privação e/ou fragilização de vínculos afetivos, 
isso implica uma atuação tanto no sentido material, de acesso à renda e bens, quanto do ponto de vista relacional, de fortalecimento de vínculos (BRASIL, 2005).

A materialização da PSB ocorre mediante ações desenvolvidas nos Centros de Referência da Assistência Social (CRAS) territorializados de acordo com o porte do município; por meio da rede de serviços socioeducativos direcionados para grupos geracionais, intergeracionais, grupos de interesse; através dos benefícios eventuais e dos benefícios de prestação continuada e através dos serviços e projetos de capacitação e inserção reprodutiva (BRASIL, 2005).

O CRAS é unidade pública estatal de base territorial e materializa os princípios de descentralização proposto na LOAS e de territorialização, conforme previsto na PNAS de 2004. O objetivo do CRAS é trabalhar com famílias e indivíduos inseridos em seu contexto comunitário, efetivando os direitos sociais dos mesmos, sobretudo, daqueles que se encontram em situação de vulnerabilidade social. O CRAS é considerado equipamento que oferta serviços, programas, projetos e benefícios de proteção social básica e que se localiza em territórios de vulnerabilidade social. Um dos principais serviços a serem executados no CRAS é o Serviço de Proteção e Atendimento Integral à Família (PAIF).

O PAIF tem finalidade de oportunizar o desenvolvimento de ações que corroborem para o fortalecimento das famílias no sentido de que as mesmas adquiram possibilidades e potencialidades de desempenhar sua função protetiva junto aos seus membros. Um trabalho realizado com as famílias a partir desse escopo gera certas expectativas, desafios, e demandas para a execução do processo de trabalho junto às famílias (BRASIL, 2012).

Cabe sublinhar que, no que concerne à função protetiva da família, não se trata apenas de impor para a mesma a função de cuidar dos seus membros, sem analisar as reais possibilidades que dispõe para desempenhar tal responsabilidade. Para que isso se efetive uma série de estratégias devem ser desenvolvidas, em que o trabalho em rede se torna fundamental, a julgar que somente a assistência social não consegue dar conta de atender demandas que são complexas e que estão relacionadas com questões macrossociais (SOUZA, 2018).

Na tabela 1 são apresentados dados do Censo SUAS de 2018, os quais ilustram o total de famílias em acompanhamento pelo PAIF no mês de agosto do referido ano. Os dados referem-se aos 8.360 CRAS que responderam ao questionário do Censo SUAS, tais equipamentos da PSB estão situados em todo o território nacional. 
Tabela 1: Total de famílias em acompanhamento pelo PAIF em agosto de 2018.

\begin{tabular}{c|c|c}
\hline & quant. de CRAS & $\%$ \\
\hline Nenhuma família & 42 & 0,5 \\
\hline Entre 1 e 20 famílias & 715 & 8,6 \\
\hline Entre 21 e 40 famílias & 975 & 11,7 \\
\hline Entre 41 e 70 famílias & 1250 & 15,0 \\
\hline Entre 71 e 100 famílias & 1037 & 12,4 \\
\hline Mais de 100 famílias & 4341 & 51,9 \\
\hline Total & 8360 & 100,0 \\
\hline
\end{tabular}

Fonte: $\operatorname{BRASIL}(2019$, p. 15).

Pouco mais de 50\% dos CRAS acompanharam no mês de agosto de 2018 mais de 100 famílias, aspecto que se torna relevante no processo de constituição de ações territorializadas que são desenvolvidas na tentativa de contribuir para a proteção social e fortalecimento dessas famílias. Em contrapartida, 0,5\% CRAS afirmaram não realizar acompanhamento de famílias no período citado. Sob esse aspecto é importante mencionar que algumas vezes a equipe de referência confunde atendimento e acompanhamento, que são atividades distintas no contexto do PAIF.

Atendimento familiar é realizado pelo profissional com intento de inserir a família, ou um de seus membros, no serviço, pressupõe ação imediata e resposta profissional qualificada, como por exemplo, a inserção da família, ou um de seus membros, em acolhida ou encaminhamentos à rede socioassistencial e/ou intersetorial. Assim, no atendimento, as demandas podem ser resolvidas em curto prazo (SOUZA, 2018).

No acompanhamento, as demandas das famílias exigem um longo prazo para serem atendidas, exigem uma série de intervenções, as quais são realizadas de forma contínua, com estabelecimento de plano de ação junto às famílias e elaboração de um Plano de Acompanhamento Familiar. Desse modo, pode ser que os CRAS que responderam que não acompanham nenhuma família, o faça efetivamente, porém, relacionam tal atividade como atendimento.

Na tabela 2 são expostos o quantitativo de famílias inseridas no PAIF no mês de agosto de 2018. 
Tabela 2: Total de novas famílias inseridas no PAIF em agosto de 2018.

\begin{tabular}{l|l|l}
\hline & quant. de CRAS & $\%$ \\
\hline Nenhuma família & 1998 & 23,9 \\
\hline Entre 1 e 20 famílias & 5309 & 63,5 \\
\hline Entre 21 e 40 famílias & 631 & 7,5 \\
\hline Entre 41 e 70 famílias & 228 & 2,7 \\
\hline Entre 71 e 100 famílias & 93 & 1,1 \\
\hline Mais de 100 famílias & 101 & 1,2 \\
\hline Total & 8360 & 100,0 \\
\hline
\end{tabular}

Fonte: BRASIL (2019, p. 15).

Número expressivo de CRAS, 63,5\% afirmaram que no período em questão foram inseridas entre 1 e 20 famílias no PAIF, oportuno destacar que o PAIF se configura como serviço e que, portanto, cumpre um interesse público, de estabelecimento de ações com escopo de proteção e atendimento das demandas familiares. Por conseguinte, o serviço vem na lógica de favorecer acesso às seguranças sociais, tem delimitação espacial, com recursos físicos e humanos específicos, com metodologia e tipificação, ou seja, não se realiza de forma aleatória, amadora, com viés caritativo, de maneira oposta, está fundamentado na perspectiva de direito social de cidadania.

Na tabela 3 são expostas informações a respeito das ações e atividades que as equipes de referências desenvolvem junto às famílias inseridas no PAIF.

Tabela 3: Ações e atividades desenvolvidas no âmbito do PAIF

\begin{tabular}{|c|c|c|}
\hline & $\begin{array}{l}\text { quant. } \\
\text { respostas }\end{array}$ & $\%$ \\
\hline 1- Acolhida em Grupo realizada por profissional de nível superior & 7266 & $6 \%$ \\
\hline 2 - Acolhida Particularizada realizada por técnica(o) de nível superior & 8142 & $6 \%$ \\
\hline 3 - Acompanhamento de famílias & 8252 & $7 \%$ \\
\hline 4 - Elaboração do Plano de Acompanhamento Familiar & 6432 & $5 \%$ \\
\hline 5 - Atendimento particularizado de famílias ou indivíduos & 8199 & $7 \%$ \\
\hline 6 - Registro do acompanhamento familiar em prontuário & 7831 & $6 \%$ \\
\hline 7 - Grupo/oficina com famílias & 7699 & $6 \%$ \\
\hline 8 - Visitas Domiciliares & 8317 & $7 \%$ \\
\hline 9 - Palestras & 7859 & $6 \%$ \\
\hline 10 - Campanhas ou eventos comunitários & 7455 & $6 \%$ \\
\hline 11 - Apoio para obtenção de Documentação pessoal & 7786 & $6 \%$ \\
\hline 12 - Encaminhamento de famílias ou indivíduos para a rede de serviço socioassistencial & 8206 & $7 \%$ \\
\hline $\begin{array}{l}13 \text { - Encaminhamento de famílias ou indivíduos para outras políticas públicas (educação, } \\
\text { habitação, trabalho etc.) }\end{array}$ & 8196 & $7 \%$ \\
\hline 14 - Encaminhamento para obtenção de Benefícios Eventuais & 8083 & $6 \%$ \\
\hline 15 - Encaminhamento para inserção/atualização de famílias no Cadastro Único & 8258 & $7 \%$ \\
\hline 16 - Acompanhamento dos encaminhamentos realizados & 7736 & $6 \%$ \\
\hline
\end{tabular}

Fonte: BRASIL (2019, p. 15). 
A execução das ações do PAIF deve ocorrer sob a perspectiva de promoção de uma série de atividades que tenham a capacidade preventiva de situações de vulnerabilidade social, essa concepção busca realizar o enfrentamento da ideia presente na execução das ações da assistência em que historicamente a intervenção se realizava após a instalação da situação de vulnerabilidade ou risco social. No contexto do CRAS prioriza-se o desenvolvimento de ações preventivas e, nesse sentido, surge a necessidade de apreensão dessa lógica de trabalho que se coloca no interior do SUAS.

Destaca-se que as atividades apresentadas na tabela 03, sejam elas materializadas de forma individual ou coletiva, devem ser norteadas pela perspectiva preventiva e protetiva.

A tabela 4 apresenta as informações a respeito das famílias que regularmente participam dos atendimentos coletivos realizados pelo PAIF, onde é possível observar que, em maior ou menor grau, há participação das mesmas nas atividades ofertadas.

Tabela 4: Total de pessoas regularmente participam atendimentos coletivos realizados pelo PAIF

\begin{tabular}{l|l|l}
\hline Entre 1 e 20 famílias & Qtde de CRAS & $\%$ \\
\hline Entre 21 e 40 famílias & 855 & $10,2 \%$ \\
\hline Entre 41 e 70 famílias & 1069 & $12,8 \%$ \\
\hline Entre 71 e 100 famílias & 1133 & $13,6 \%$ \\
\hline Mais de 100 famílias & 847 & $10,1 \%$ \\
\hline Total & 2729 & $32,6 \%$ \\
\hline Missing System & 6633 & $79,3 \%$ \\
\hline Total & 1727 & $20,7 \%$ \\
\hline
\end{tabular}

Fonte: BRASIL (2019, p. 16).

O PAIF parte do pressuposto da realização de trabalho social com as famílias atendidas, no entanto é importante sinalizar que este trabalho deve priorizar uma metodologia em que fique claro o referencial teórico adotado pela equipe, pois as ações do PAIF ainda que realizadas num contexto de proposta progressista e emancipatória, podem ser materializadas com o viés de enquadramento e responsabilização.

Portanto, a respeito da tabela 04 e o quesito participação, Souza (2018) problematiza que muitas vezes as famílias que participam de reuniões coletivas são impelidas ao cumprimento de metas estabelecidas junto aos programas sociais, assim, são convocadas para estarem presentes em inúmeras reuniões, tanto no CRAS, como na saúde e na escola. Aspecto que gera desgaste na família, principalmente se o teor das reuniões tiver como premissa a culpabilização, o reforço da incompetência familiar em prover seu 
próprio sustento, em cumprir função protetiva e não responder às aspirações sociais que são impostas sobre ela.

O caderno de Orientações Técnicas sobre o PAIF (BRASIL, 2012) sinaliza que o trabalho social com as famílias corresponde a uma série de procedimentos que devem se fundamentar em princípios teórico-metodológicos, técnico-operativos e éticos-políticos com vistas a favorecer um processo de convivência, de identificação de direitos e possibilidades no contexto de vida das famílias. As ações do PAIF servirão de apoio às famílias, isto é, terão a finalidade de contribuir para que as mesmas percebam que as situações de privações, de vulnerabilidades não ocorrem tão somente em decorrência de sua incapacidade, mas que, sobretudo, essas situações se inserem em um contexto maior de estrutura social.

Tendo isso em vista, a tabela 05 apresenta as principais temáticas abordadas junto aos grupos coletivos realizados pelo PAIF. Sublinha-se que as temáticas são diversas, as quais correspondem principalmente com o acesso aos direitos sociais referentes à renda, documentação civil, direito a lazer e cultura, direito à alimentação, direito das mulheres etc.

Sobre o direito às mulheres, ressalta-se a atualidade da temática, bem como o fato de que, ao se referir à instituição família, nos espaços das políticas sociais, relaciona-se a responsabilidade à mulher, o que gera sobrecarga sobre a mesma.

Tabela 5: Em 2018, quais as cinco principais temáticas abordadas nos atendimentos coletivos realizados pelo PAIF

\begin{tabular}{l|l|l}
\hline & No respostas & $\%$ \\
\hline $\begin{array}{l}\text { - Não há grupos do PAIF } \\
2 \text { - Direito à transferência de renda e benefícios assistenciais }\end{array}$ & 454 \\
\hline $\begin{array}{l}\text { - Direito a Documentação Civil Básica (certidão de nascimento, CPF, RG, título } \\
\text { eleitoral) }\end{array}$ & 5932 & $16 \%$ \\
\hline 4 - Direito a cultura e lazer & 3290 & $9 \%$ \\
\hline 5 - Direito das Mulheres & 1642 & $4 \%$ \\
\hline 6 - Direitos das pessoas com deficiência & 5547 & $15 \%$ \\
\hline 7 - Direito à Alimentação & 3342 & $9 \%$ \\
\hline 8 - Os direitos das famílias & 1754 & $5 \%$ \\
\hline 9 - As especificidades do ciclo vital dos membros das famílias & 5106 & $14 \%$ \\
\hline 10 - Cuidar de quem cuida & 1384 & $4 \%$ \\
\hline 11 - O uso de álcool e/ou outras drogas na família & 1481 & $4 \%$ \\
\hline 12 - Problemas e soluções do território & 3503 & $9 \%$ \\
\hline 13 - Diversidade cultural, étnica e social & 1109 & $3 \%$ \\
\hline 99 - Outro & 1535 & $4 \%$ \\
\hline
\end{tabular}

Fonte: BRASIL (2019, p. 16). 
As vivências de situações de desproteção social relacionam-se com o modo de organização social e a forma como o Estado desenvolve, ou não, estratégias de enfrentamento a tais situações. Assim, as intervenções do PAIF necessitam ser orientadas para a construção de estratégias que operem no viés de prevenção das situações de vulnerabilidades.

Como visualizado na tabela 03 , as ações do PAIF podem ser desenvolvidas de forma individual ou coletiva por meio de: acolhida (individual/familiar); encaminhamentos (individual/familiar); oficinas com famílias; ações comunitárias; ações individuais. Essas atividades têm objetivo de materializar a proteção social afetada à área da assistência social, pois:

[...] o alcance dos objetivos do PAIF não deve ser algo abstrato ou apenas presente no discurso. Os objetivos do Serviço devem ser buscados ao longo de todo seu processo de implementação. Portanto, são os objetivos do PAIF os principais elementos a serem considerados ao se formatar a acolhida, planejar as oficinas com famílias, subsidiar as ações particularizadas, avaliar os impactos de uma ação comunitária ou de um encaminhamento realizado, por exemplo (BRASIL, 2012, p. 15).

Esta forma de execução das ações da PSB no contexto dos CRAS requer dos profissionais aquisição de novas competências e habilidades que até então não eram um requisito para a materialização das ações na área da assistência social.

Conforme os princípios e diretrizes do SUAS, a equipe de referência profissional atuante no CRAS deve ser interdisciplinar e composta por: Assistente Social, Psicólogo e até mesmo profissional de Pedagogia. Parte do pressuposto de que nenhum especialista, de modo isolado, tem condições de oferecer uma abordagem integral ao usuário (CAMPOS; DOMITTI, 2007). A PNAS expõe que o SUAS, ao concretizar a garantia de proteção social ativa, opera mediante à perspectiva de oportunizar um processo de aquisição de condições de autonomia, resiliência e de protagonismo cidadão dos usuários, desafiando os profissionais a desenvolverem suas práticas em consonância com estas diretrizes.

Importante evidenciar que o fazer profissional da equipe de referência do CRAS tem o compromisso de ser orientada por uma abordagem teórica que busque problematizar o cotidiano social, no sentido de não apenas reproduzir uma prática pragmática e empirista, mas que ao contrário, realize um processo de reflexão sobre o contexto social. 
Emerge a necessidade de executar uma prática profissional que se move a partir de conhecimento científico, fruto de uma reflexão, que tem na práxis o fazer profissional. Aspecto que aliás, qualifica a ação fornecendo elementos que contribuem para desmitificar a normalidade do cotidiano, problematizando a injusta estrutura social produzida e reproduzida na sociabilidade capitalista.

O trabalho a ser desenvolvidos junto às famílias inseridas no PAIF deve estar imbuído de intencionalidades, portanto, as ações devem seguir um rigoroso planejamento ao invés de se realizarem de forma aleatória. Nesse sentido, a filosofia da práxis, sustentada em Gramsci, pode ser referência para pautar as práticas profissionais no âmbito do PAIF.

\section{Pressupostos contidos na Filosofia da práxis como mobilizadores das práticas profissionais}

A filosofia da práxis ancorada no pensamento de Gramsci $(1978,1999,2000)$ tem como pressuposto que há no meio popular um conhecimento, um senso comum que precisa ser aprofundado, que precisa ser elevado ao bom senso. Com a passagem do senso comum ao bom senso, as classes subalternizadas teriam a possibilidade de acionar processos de rupturas, concernentes às visões de mundo das classes dominantes e adquirir, progressivamente, consciência da potencialidade histórica da práxis humana (SEMERARO, 2001).

Para Gramsci, todos os homens são filósofos, porque todos possuem uma filosofia de vida, ainda que espontânea, que se manifesta no cotidiano imediato, há uma filosofia contida no senso comum que deriva da experiência prática/concreta dos sujeitos e das classes subalternas.

Recuperar a ideia de que todos são filósofos implica em se posicionar de forma a enfrentar a concepção de que a filosofia é algo restrito aos intelectuais, aos cientistas especializados em determinado assunto e reconhecer que há um saber produzido no meio das classes subalternas (GRAMSCI, 2013). Diante de tal constatação Valla (1996) chama a atenção para a necessidade de se prestar mais atenção ao que a periferia, ao que as classes subalternas dizem, pois muitas vezes, ao não realizar uma escuta atenta, interpreta-se a sua fala de forma equivocada.

A mais simples atividade intelectual contém uma concepção de mundo, não se trata apenas de um conjunto de noções e palavras sem sentido, visto que são concepções 
que derivam da experiência concreta de vida (GRAMSCl, 2013). Assim sendo, cabe a seguinte reflexão: como as famílias inseridas no PAIF pensam e percebem o mundo ao seu redor? São famílias que possuem uma bagagem de conhecimentos e concepções de mundo que são elaboradas a partir de sua vivência na comunidade, no território em que estão inseridas e, consequentemente podem auxiliar a fazer a análise necessária para a gestão territorial, tarefa que deve ser cumprida pelo CRAS em termos de promover um olhar das vulnerabilidades sociais mais constantes no seu território de abrangência.

Ao reconhecer que as classes subalternas também têm uma filosofia e concepção de mundo, Gramsci (2013) afirma "O início da elaboração crítica é a consciência daquilo que é realmente, isto é, um "conhece-te a ti mesmo" como produto do processo histórico até hoje desenvolvido, que deixou em ti uma infinidade de traços acolhidos sem análise crítica" (GRAMSCI, 2013, p. 94). Junto às famílias inseridas no PAIF é importante criar condições para que elas desvelem o movimento histórico que produz e reproduz a subalternidade de sujeitos que se encontram em situação de pobreza ou de vulnerabilidade social.

Historicamente as ações da assistência social foram efetivadas mediante processo de responsabilização e de culpabilização das famílias por não conseguirem dar conta de sua sobrevivência e terem de recorrer aos serviços públicos em busca de atendimento de suas demandas. E, na mesma medida em que se culpabilizava as famílias, as mesmas assumiam postura de fracasso e de incapacidade, colocando-se em uma situação de pessoas que precisam de um "tutor", pois acreditavam não ter competência para prover sua subsistência (VALLA, 1996).

A esse respeito, recorre-se a Gramsci (2003, p. 97) que afirma que muitas vezes um grupo social:

[...] toma emprestado a outro grupo social, por razões de submissão e subordinação intelectual, uma concepção que não é a sua, e a afirma verbalmente, e também acredita segui-la, [...] quando a conduta não é independente e autônoma, mas sim submissa e subordinada.

Essa forma de conceber as famílias atendidas no âmbito da política pública de assistência social tem sido enfrentada, basta consultar as diversas normativas que respaldam o SUAS e que remetem à ideia de construção e defesa de um projeto societário com mais igualdade, equidade e justiça social e de reconhecimento das possibilidades das famílias e não somente de suas fragilidades. 
Em Gramsci é possível encontrar fundamentos que instrumentalizem a reflexão necessária a ser realizada pela equipe profissional do CRAS, analisar as demandas das famílias inseridas no PAIF numa visão de totalidade e não apenas uma visão da demanda aparente. A demanda real, que faz com que inúmeras famílias busquem a proteção social afeta à área da assistência social, tem origem na estrutura organizacional da sociedade, ou seja, a origem dessa demanda não se concentra no limite ou incapacidade da família.

Nessa linha de raciocínio, cabe ponderar a respeito da relevância dos usuários da política de assistência social serem "[...] convocados e mobilizados para discutir suas reais demandas e a própria política [...]" e ainda, "[...] desenvolver e apurar a visão crítica de sua realidade, de seus companheiros e da grande massa da sociedade brasileira" (OLIVEIRA, 2011, p. 255).

Concernente a isso a equipe profissional do CRAS pode incentivar e apoiar as:

[...] formas coletivas de trabalho, como mutirões, associações e grupos coletivos; na mobilização e organização das famílias trabalhadoras para inserirem-se nos processos de educação formal e política, tidas como fundamentais para o avanço da consciência de classe; e na produção e socialização de conhecimentos que contribuam para o fortalecimento de sujeitos coletivos (DURIGUETTO; BALDI, 2012, p. 198).

Valla (1996) alerta que a crise de interpretação é nossa quando há a proposição de dialogar com as classes populares, visto que é necessário realizar um esforço de entender suas falas e considerar suas experiências. O que parece ser retrato de um conformismo sem fim, para a realidade de uma família, que cotidianamente vivencia a experiência da ausência de direitos e de proteção social, é avanço. O autor chama a atenção para a forma como os profissionais colocam-se para dialogar junto aos grupos populares quando pondera sobre a seguinte situação:

\footnotetext{
Quantas vezes se pede para população se manifestar numa reunião, como prova do nosso compromisso com a "democracia da classe média"? Mas, uma vez passada a fala popular, procuramos voltar "ao assunto em pauta", entendendo que a fala popular foi uma interrupção necessária, mas com certeza, sem conteúdo e sem valor (VALLA, 1996, p. 182).
}

O trecho pode auxiliar na problematização sobre, em que medida, usa-se a “[...] Política de Assistência como forma de controle e apassivamento de diferentes segmentos da classe trabalhadora. As políticas desmobilizam ao invés de mobilizarem"? (FARAGE, 
2011, p. 264). Nessa linha de raciocínio pode-se afirmar que, mesmo no PAIF, podem ser reeditadas estratégias de assistencialismo.

Se, a política de assistência contribui para desmobilizar, Farage (2011) argumenta que assim é possível entender o pensamento de muitos usuários, quando da necessidade de se inserir no Programa Bolsa Família para atendimento de uma necessidade de subsistência, achar que talvez no próximo mês dê certo, mantendo postura de passividade ao contrário de reivindicar a sua inserção no Programa a partir de processo de mobilização coletiva e de luta pelos seus direitos.Essa situação sinaliza que as políticas sociais podem contribuir para processos de desmobilização.

\begin{abstract}
É necessário tomar como premissa "o pensamento radical e simples das classes exploradas, meio e instrumento (ao invés de instrumentalizá-las), para desvendar o lado oculto das relações sociais com os olhos destas, revelando-lhes aquilo que ele enxerga mas não vê, completando com ele, a produção do conhecimento crítico que nasce da revelação do subalterno como sujeito" (VALLA, 1996, p. 184).
\end{abstract}

Esse é um dos pressupostos contidos na filosofia da práxis elaborada por Gramsci (2013), segundo o qual é necessário considerar todo indivíduo/ser humano como filósofo. Este é um projeto societário que se realiza levando em conta a capacidade do ser humano de se tornar um sujeito consciente de sua posição histórica no mundo. É um processo que se efetiva mediante a crítica do conhecimento estabelecido na sociedade capitalista, de forma a conduzir o ser humano a não de conformar à realidade, buscando a construção de uma nova sociabilidade, cuja premissa seja o resgate dos valores humanos e de civilidade emancipatórios.

Trata-se de propagar e disseminar uma concepção de mundo que considere o ser humano como um:

[...] "conjunto das relações sociais" (Q 10, 1337), de relações não vagas e abstratas, mas dialeticamente concretas, consideradas dentro de precisas condições de trabalho, de um modo de produção material e simbólico, de divisões de classe, de distribuição da riqueza e do poder no mundo que nos engloba (SEMERARO, 2005, p. 31).

O autor em questão chama a atenção para considerar o ser humano como resultado do conjunto das relações sociais. Assim é necessário nomear as relações concretas de vida nas quais o indivíduo está inserido, analisando o modo de produção da 
vida material e os fundamentos ontológicos da sociedade capitalista, as correlações de forças que perpassam as relações sociais para, então, perceber os condicionantes objetivos que limitam o subalterno a se constituir como sujeito histórico.

[...] se o subalterno era ontem uma coisa, hoje não mais o é: tornou-se uma pessoa histórica, um protagonista; se ontem era irresponsável, já que "resistia" a uma vontade estranha, hoje sente-se responsável, já que não é mais resistente mas sim agente e necessariamente ativo e empreendedor. Mas, mesmo ontem, será que ele era apenas simples "paciente", simples "coisa", simples "irresponsabilidade"? Não, por certo (GRAMSCI, 1995, p. 106-107).

Uma intervenção, como a acolhida ou oficina junto às famílias, por exemplo, quando fundamentada na filosofia da práxis contribui para que tanto os profissionais, como as famílias atendidas no PAIF construam análises e constatações do ser humano como produtor e sujeito na história da humanidade, esse olhar fornece a percepção das possibilidades contidas no ser humano e ao mesmo tempo a visualização dos eventos que foram se estabelecendo com vistas à sua subalternidade. A análise, tanto do passado histórico como do tempo presente, configura-se como condição necessárias para que se tenha um ponto de partida de constituição de ações que colaborem com a identificação de direitos e possibilidades no contexto de vida das famílias inseridas no PAIF. Assim, na sequência tratar-se-á de elementos específicos a respeito do trabalho social com famílias.

\section{Apontamentos sobre o trabalho social com famílias}

Não é possível avançar nas reflexões sobre o trabalho social com famílias sem fazer referência à ofensiva neoliberal que impacta nas políticas de proteção social, especialmente da assistência social (aqui em foco). Mota, Maranhão e Sitcovsky (2010), ao analisar a Seguridade Social e sua expansão no século $X X$, bem como os ajustes econômicos decorrentes da ação do grande capital e organismos financeiros internacionais, afirmam que:

[...] presencia-se abertamente a investida da classe dominante contra a seguridade social brasileira, momento em que explicita a sua ideologia de enfrentamento da 'questão social': a mercantilização de serviços sociais vis-a-vis com a expansão de políticas sociais compensatórias (MOTA; MARANHÃO; SITCOVSKY, 2010, p. 185). 
As autoras, reforçam, que a "descontinuidade" ainda é uma das características que marcam a política de Assistência Social no Brasil, agravada pela "regressão de políticas redistributivas de natureza púbica e constitutiva de direitos, em prol de políticas compensatórias de 'combate à pobreza', de caráter seletivo e fragmentário" (MOTA; MARANHÃO; SITCOVSKY, 2010, p. 182).

Neste cenário, a matricialidade sociofamiliar, como um dos eixos estruturantes da política, impõe um desafio crucial ao trabalho social com famílias, o qual é desempenhado por profissionais no âmbito da proteção social básica, desafio que consiste em romper com processos de responsabilização das famílias pela garantia de proteção e bem-estar de seus membros.

Teixeira (2015), alerta que é preciso reconhecer as contradições presentes no desenho da PNAS, a qual demarca a família e suas demandas como acionadoras da implementação dos benefícios, serviços, programas e projetos, reconhecendo-a como sujeito coletivo de direito à proteção social. Mas, por outro lado, potencializa-se os papéis da família em relação à socialização dos seus membros, proteção e prevenção de situações de vulnerabilidade e/ou risco social, considerando-a espaço de construção de vínculos afetivos e sociais. Trata-se de:

[...] um descompasso entre a importância atribuída ao papel da família e a falta de condições mínimas de vida digna e de suporte e serviços familiares ofertados pelo poder público, o que mostra que na prática ocorre mesmo é uma responsabilização da família pela proteção social de seus membros (TEIXEIRA, 2015, p. 216-217).

A intervenção do Estado ocorre quando a família falha quanto às suas responsabilidades de cuidado e proteção, sendo tardia e subsidiária. As famílias são identificadas como parceiras, compondo parte da rede de proteção social e estão sujeitas a condicionalidades para acessar e se manter em serviços e benefícios ofertados pela política pública. Reforçando as reflexões de Teixeira (2015), a centralidade da família nas políticas sociais é fundamental, mas na perspectiva de inclusão social. Para tanto, é preciso oferta universal e continuada de serviços, que garantam suporte, cuidados aos membros vulneráveis por problemas de saúde ou próprios do ciclo de vida, qualificação profissional, trabalho e renda, atividades culturais, de lazer e esporte e acesso às demais políticas que garantam seus direitos essenciais. 
Neste contexto contraditório, que anuncia garantir oferta de serviços de natureza inclusiva, é que urge refletir sobre o trabalho social com famílias no âmbito da proteção social básica, rompendo com a fragmentação e com a responsabilização da família que vivencia em seu cotidiano as diversas manifestações da questão social, sem a devida proteção social preconizada pelas políticas públicas.

A matricialidade sociofamiliar, como eixo estruturante da PNAS, aponta como desdobramento a necessidade de pensar o trabalho concreto a ser desenvolvido com famílias em condição de vulnerabilidade ou risco social. No entanto, uma preocupação central é importante neste debate: o de não substituir a proposição de ordem teórica e metodológica pelo caráter instrumental das possibilidades interventivas junto aos usuários do CRAS e programas específicos como o PAIF.

Esta preocupação é reafirmada por Mioto (2010, p. 172), ao expressar que a ação dos profissionais no âmbito das Políticas Públicas deve ser orientada por uma teleologia, ou seja: "Para além de sua eficiência operativa ou de sua instrumentalidade. Portanto, há necessidade de incorporar a ela o compromisso ético com a transformação social, que nesse contexto sócio-histórico se traduz em conquista e garantia de direitos."

Nesta perspectiva e ainda conforme Mioto (2010, p. 173), a intervenção junto à família deve avançar para além da dimensão singular. Assim, deve se encaminhar para os seguintes níveis: "proposição, articulação e avaliação de políticas sociais, organização e a articulação de serviços e atendimento a situações singulares."

O primeiro nível - proposição, articulação e avaliação de políticas sociais envolve diagnóstico ou estudo das demandas familiares objetivando subsidiar a avaliação do impacto das políticas e o encaminhamento de ações destinadas ao controle social. 0 segundo nível - organização e a articulação dos serviços - deve preconizar uma estrutura de cuidado e proteção, ou seja, que a estrutura e funcionamento dos serviços ofertados à família possibilitem eficácia no atendimento de suas demandas, bem como a sua participação na gestão da política em nível local. O terceiro nível - atendimento às situações singulares - tem como foco de atenção as dificuldades enfrentadas pelas famílias, as relações internas e as potencialidades de mudanças que, latentes, podem ser trabalhadas de forma articulada à rede de proteção social em que estejam engajadas (MIOTO, 2010). 
A autora amplia o debate proposto em torno do trabalho com famílias, indicando que tais níveis de intervenção se estruturam em processos político-organizativos, processos de planejamento e gestão e processos socioassistenciais. Os dois primeiros processos envolvem a dimensão coletiva e o fortalecimento da esfera de proteção social destinada a garantir os direitos sociais das famílias e o acesso às demais políticas públicas. Ênfase deve-se dar ao caráter de intersetorialidade das políticas públicas quando se trata do planejamento e gestão em nível institucional (MIOTO, 2010).

É importante destacar os processos socioassistenciais que, na orientação de Mioto (2010, p. 174):

[...] correspondem às ações profissionais desenvolvidas diretamente com as famílias. Sua lógica reside em atendê-las enquanto sujeitos e não como objetos terapêuticos. Assim, busca-se responder às suas demandas/necessidades numa perspectiva de construção da autonomia. Autonomia que Ihes permitam um engajamento ativo no contexto da participação política.

Gueiros (2010, p. 129) levanta um aspecto complementar a este debate sobre trabalho com famílias vulnerabilizadas, a estruturação da rede de serviços no espaço territorial do CRAS "que inclui o constante diálogo entre as diferentes organizações, na perspectiva de evitar descontinuidades, lacunas e sobreposições de ações." Neste caso, trata-se de garantir atendimento eficiente às demandas familiares, evitando o agravamento das situações que levam à fragilização das relações e vínculos familiares.

\footnotetext{
Desse modo, o trabalho social com famílias abarca procedimentos relativos à rede de bens e serviços do território e atenção individualizada e coletiva à população usuária, realizados de forma regular e frequente. Deve contemplar igualmente a interdisciplinaridade (articulação das políticas de saúde, educação, educação, assistência e habitação, entre outras) e zelar pela permanência a médio e longo prazo dos programas e serviços oferecidos, posto que as famílias já vivem múltiplas instabilidades (de trabalho, de domicílio, da rede de suas relações sociais primárias, por exemplo) e não podem ser submetidas também aos projetos que não se constituam em políticas de longo alcance, em termos dos recursos necessários e de um tempo viável ao processo de autonomia e de emancipação da família (GUEIROS, 2010, p. 130).
}

Esta proposição de trabalho de fortalecimento da rede de serviços socioassistenciais exige obrigatoriamente pensar a gestão da Política de Assistência Social em nível local, que além de ser participativa e descentralizada, deve orientar-se por 
valores éticos e políticos que promovam processos de autonomia das famílias e de exercício da cidadania.

Bourguignon (2008, p. 255) elenca, para o trabalho com famílias, alguns desafios "que passam pela gestão das políticas públicas, pela avaliação e pelo controle social dos recursos que financiam tais ações". Neste contexto, os desafios são: capacitação dos profissionais; desenvolvimento de práticas interdisciplinares e construção de metodologias voltadas para o fortalecimento do protagonismo da família.

A capacitação dos profissionais, de forma permanente e continuada objetiva oportunizar processos de rompimento com concepções e valores conservadores em torno dos arranjos familiares, que muitas vezes culpabilizam as famílias pelas condições socioeconômicas e pela fragilização de vínculos em que vivem, contribuindo com os mecanismos de desresponsabilização do Estado diante da precarização das ofertas de ações e programas no contexto das políticas públicas. Igualmente importante, as capacitações oportunizam avaliar as práticas desenvolvidas e redirecioná-las de acordo com as demandas concretas das famílias (BOURGUIGNON, 2008).

As ações profissionais no âmbito do SUAS devem ser interdisciplinares, considerando as complexidades das demandas apresentadas pelas famílias. "Da relação desafiadora e do diálogo inquietante com outras áreas de conhecimento que se dá no cotidiano que é possível construir relações e práticas emancipatórias." (BOURGUIGNON, 2008, p. 236).

Por fim, construir metodologias que fortaleçam o protagonismo das famílias impõe compreender a concepção de metodologia. Metodologia implica em "[...] formas de condução das ações profissionais em determinado momento tendo em vista a efetivação de determinados objetivos e finalidades. Portanto elas não podem ser construídas à priori, masno processo." (MIOTO, 2010, p. 175).

A potencialidade do trabalho com famílias é imenso, "sobretudo exige o reconhecimento da capacidade destas famílias de conhecer e intervir em sua própria realidade com autonomia, desvencilhando-se das estratégias de assistencialismo, clientelismo e de cristalização das condições de subalternidade." (BOURGUIGNON, 2008, p. 256). Alerta-se, no entanto, que o protagonismo da família não significa isentar o Estado de sua responsabilidade na oferta de serviços de qualidade e de forma articulada às demais políticas públicas. 


\section{Conclusões}

Refletir sobre as possibilidades de trabalho social com famílias é relevante diante do contexto em que se observam, no cenário nacional, ameaças permanentes de desmonte das políticas públicas. O cenário socioeconômico aponta para regressão dos direitos sociais da família e fragmentação das ações desenhadas pelas políticas públicas, rompendo com seu caráter protetivo. E é neste contexto, que o trabalho social com famílias deve ganhar força e direção social, rompendo com processos de responsabilização da família, que vulnerabilizada ou em situação de risco social, não encontra na rede de serviços socioassistenciais garantia de acesso aos seus direitos sociais.

O trabalho social com famílias viabiliza a materialização da proteção social nos CRAS, especialmente através dos serviços executados pelo PAIF. O PAIF deve oportunizar o desenvolvimento de ações que fortaleçam as famílias nas suas atribuições protetivas. Tais ações devem ser continuadas e diagnosticar vulnerabilidades, enfrentá-las e vislumbrar potencialidades.

Para tanto, metodologias pautadas na participação e protagonismo das famílias devem ser construídas mediante o reconhecimento das demandas que chegam até o CRAS e a equipe profissional. Demandas complexas que exigem práticas de caráter interdisciplinar e ação intersetorial no campo da gestão das políticas públicas.

A perspectiva teórica que pavimenta essas reflexões e as proposições retratadas neste artigo estão sustentadas na filosofia da práxis, portanto tem em seu horizonte o reconhecimento famílias como sujeitos de direitos e portadoras de conhecimentos e experiências sociais favorecedoras do exercício de seu protagonismo e autonomia.

\section{Referências}

BOURGUIGNON, J. A. Proteção social e família: reflexões sobre alguns desafios presentes nesta relação. In: COSTA, L. C. (org.). Estado e democracia: pluralidade de questões. Ponta Grossa: Editora UEPG, 2008. p. 247-259.

BRASIL. Ministério do Desenvolvimento Social e Combate à Fome. Orientações técnicas sobre o PAIF. Brasília: Ministério do Desenvolvimento Social e Combate à Fome, 2012. v. 2.

BRASIL. Ministério do Desenvolvimento Social e Combate à Fome. Política Nacional de Assistência Social: norma operacional básica - NOB/SUAS. Brasília: Ministério do Desenvolvimento Social e Combate à Fome, 2005. 84 p. 
BRASIL. Secretaria Nacional de Assistência Social. Censo SUAS 2018: Resultados Nacionais, Centro de Referência da Assistência Social - CRAS. Brasília: Secretaria Nacional de Assistência Social, 2019.

CAMPOS, G. W. S.; DOMITTI, A. C. Apoio matricial e equipe de referência: uma metodologia para gestão do trabalho interdisciplinar em saúde. Caderno de Saúde Pública, Rio de Janeiro, v. 23, n. 2, p. 399-407, fev. 2007. DOI: 10.1590/S0102$311 \times 2007000200016$.

DURIGUETTO, M. L.; BALDI, L. A. P. Serviço Social, mobilização e organização popular: uma sistematização do debate contemporâneo. Revista Katálysis, Florianópolis, v. 15, n. 2, p. 193-202, dez. 2012. DOI: 10.1590/S1414-49802012000200005.

FARAGE, E. O trabalho do/a assistente social no SUAS. In: CONSELHO FEDERAL DE SERVIÇO SOCIAL - CFESS. O trabalho do/a Assistente Social no SUAS: Seminário Nacional. Brasília: CFESS, 2011. p. 259-270. (Gestão Atitude Crítica para Avançar na Luta).

GRAMSCI, A. Os intelectuais e a organização da cultura. Rio de Janeiro: Civilização Brasileira,1978.

GRAMSCI, A. Concepção dialética da história. Tradução de Carlos Nelson Coutinho. 10. ed. Rio de Janeiro: Ed. Civilização Brasileira, 1995.

GRAMSCl, A. Cadernos do Cárcere. Vol.3. Maquiavel: notas sobre o Estado e a Política. Rio de Janeiro: Ed. Civilização Brasileira. 2000. 432 p.

GRAMSCI, A. Cadernos do Cárcere. Tradução de Carlos Nelson Coutinho. Rio de Janeiro: Civilização Brasileira, 2013. v. 1.

GUEIROS, D. A. Família e trabalho social: intervenções no âmbito do serviço Social. Revista Katálysis, Florianópolis, v. 13, n. 1, p. 126-132, jan./jun. 2010. DOI: 10.1590/S141449802010000100015.

JACCOUD, L. Proteção Social no Brasil: debates e desafios. In: CONCEPÇÃO e gestão da proteção social não contributiva no Brasil. Brasília: Ministério do Desenvolvimento Social e Combate à Fome, 2009. p. 57-86.

MIOTO, R. C. Família, trabalho com famílias e Serviço Social. Serviço Social em Revista, Londrina, v. 12, n. 2, p. 163-176, jan./jun. 2010. DOI: http://dx.doi.org/10.5433/16794842.2010v12n2p163.

MOTA, A. E.; MARANHÃO, C. H.; SITCOVSKY, M. As tendências da política de Assistência Social, o Suas e a formação profissional. In: MOTA, A. E. (org.). O Mito da Assistência Social: ensaios sobre o Estado, Política e Sociedade. 4. ed. São Paulo: Cortez Editora, 2010. p. $180-198$.

OLIVEIRA, H. C. Assistência social, mobilização e educação popular. In: CONSELHO FEDERAL DE SERVIÇO SOCIAL - CFESS. O trabalho do/a Assistente Social no SUAS: Seminário Nacional. Brasília: CFESS, 2011. p. 249-258. (Gestão Atitude Crítica para Avançar na Luta). 
SEMERARO, G. Anotações para uma teoria do conhecimento em Gramsci. Revista Brasileira de Educação, Rio de Janeiro, n. 16, p. 95-104, jan./abr. 2001. Disponível em: http://www.scielo.br/pdf/rbedu/n16/n16a09. Acesso em: 20 abr. 2014. ISSN 1413-2478. DOI: http://dx.doi.org/10.1590/S1413-24782001000100010.

SEMERARO, G. Filosofia da práxis e (neo) pragmatismo. Revista Brasileira de Educação, Rio de Janeiro, n. 29, p. 28-39, ago. 2005. Disponível em:

http://www.scielo.br/pdf/rbedu/n29/n29a03.pdf. Acesso em: 5 maio 2014. ISSN 14132478. DOI: http://dx.doi.org/10.1590/S1413-24782005000200003.

SOUZA, C. G. Sistema Único de Assistência Social: a proteção e o atendimento à família. Ponta Grossa: Ed. UEPG, 2018. 188 p.

TEIXEIRA, S. M. Política social contemporânea: a família como referência para as Políticas Sociais e para o trabalho social. In: MIOTO, R. C. T.; CAMPOS, M. S.; CARLOTO, C. M. Familismo, direitos e cidadania: contradições da política social. São Paulo: Cortez Editora, 2015. p. 211-239.

VALLA, V. V. A crise de interpretação é nossa: procurando compreender a fala das classes populares. Educação e Realidade, Porto Alegre, v. 21, n. 2, p. 177-190, 1996. Disponível em: https://seer.ufrgs.br/educacaoerealidade/article/view/71626/40626. Acesso em: 10 abr. 2018. 